\title{
BMJ Open Validation of a survey tool to assess the patient safety attitudes of pharmacy students
}

\author{
Ramesh L Walpola, ${ }^{1}$ Romano A Fois, ${ }^{1}$ Stephen R Carter, ${ }^{1}$ Andrew J McLachlan, ${ }^{1,2}$
} Timothy F Chen ${ }^{1}$

To cite: Walpola RL, Fois RA, Carter SR, et al. Validation of a survey tool to assess the patient safety attitudes of pharmacy students. BMJ Open 2015;5:e008442. doi:10.1136/bmjopen-2015008442

- Prepublication history and additional material is available. To view please visit the journal (http://dx.doi.org/ 10.1136/bmjopen-2015008442).

Received 8 April 2015 Revised 15 July 2015 Accepted 31 July 2015

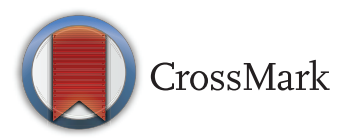

${ }^{1}$ Faculty of Pharmacy, The University of Sydney, Sydney, New South Wales, Australia ${ }^{2}$ Centre for Education and Research on Ageing, Concord Repatriation General Hospital, Concord, New South Wales, Australia

Correspondence to Ramesh Walpola; ramesh. walpola@sydney.edu.au

\section{ABSTRACT}

Objective: Patient safety education is a key strategy to minimise harm, and is increasingly being introduced into junior pharmacy curricula. However, currently there is no valid and reliable survey tool to measure the patient safety attitudes of pharmacy students. This study aimed to validate a modified survey tool, originally developed by Madigosky et al, to evaluate patient safety attitudes of junior pharmacy students.

Design: A 23-item cross-sectional patient safety survey tool was utilised to evaluate first and second year pharmacy students' attitudes during May 2013 with both exploratory and confirmatory factor analyses performed to understand the psychometric properties of the survey tool and to establish construct validity.

Setting: Undergraduate university students in Sydney, Australia

Participants: 245 first year and 201 second year students enrolled in the Bachelor of Pharmacy Programme at The University of Sydney, Australia in May 2013.

Results: After exploratory factor analysis on first year student responses (55.76\% variance explained) and confirmatory factor analysis on second year responses, a 5-factor model consisting of 14 items was obtained with satisfactory model fit $\left(\chi^{2}(66)=112.83, p<0.001\right.$, RMSEA $=0.06, C F I=0.91)$ and nesting between year groups $\left(\Delta \chi^{2}(7)=3.079, p=0.878\right)$. The five factors measured students' attitudes towards: (1) being quality improvement focused, (2) internalising errors regardless of harm, (3) value of contextual learning, (4) acceptability of questioning more senior healthcare professionals' behaviour and (5) attitude towards open disclosure.

Conclusions: This study has established the reliability and validity of a modified survey tool to evaluate patient safety attitudes of pharmacy students, with the potential for use in course development and evaluation.

\section{INTRODUCTION}

Patient safety has become a key priority for health systems around the world since the publication of the seminal reports To Err is Human $^{1}$ and An Organisation with a Memory ${ }^{2}$ 15 years ago. In 2002, the World Health

\section{Strengths and limitations of this study}

- Although there are many studies evaluating the patient safety attitudes of health care professionals, there is no validated published survey tool to evaluate the patient safety attitudes of pharmacy students.

- This study adapted one of the most highly utilised survey tools that measure patient safety attitudes of healthcare students in order to suit pharmacy students.

- This survey tool was then validated using a rigorous analytical approach, employing both exploratory and confirmatory factor analyses.

- This validated survey tool can be used to measure and evaluate the effectiveness of patient safety interventions across five key domains.

Organization (WHO) member states recognised the need to reduce the harm and suffering that patients and their families experience from healthcare errors, and agreed on a resolution to improve patient safety. Education has since been considered a crucial element in minimising patient harm. ${ }^{3}$ In 2011, the WHO published a multiprofessional Patient Safety Curriculum Guide to assist healthcare schools to implement patient safety education. ${ }^{4}$ However, the implementation of patient safety specific education can be challenging in already full university teaching curricula. ${ }^{5}$

Most pharmacy degree programmes currently include education on some elements from the WHO curriculum, including aspects related to medication safety, communication and patient-centred care. ${ }^{6}$ Many students now gain work experience in healthcare settings at an earlier stage of their degrees, either through experiential placements or through casual employment and therefore, there is a greater emphasis on the need to integrate patient safety education earlier on in professional degree 
programmes. $^{7} 8$ In response to this, many pharmacy schools now incorporate patient safety education earlier in the curriculum. ${ }^{910}$ Although evaluating patient safety knowledge is a key consideration when undertaking curriculum evaluation, it is also crucial that patient safety attitudes are understood and evaluated. This is particularly important in light of evidence that attitudes can considerably influence behaviours. ${ }^{11}$

There are a number of survey tools that have been used to the measure patient safety attitudes and values of healthcare students, each to varying degrees. ${ }^{9} 10$ 12-19 The most widely adapted and validated tool is the Patient Safety/Medical Fallibility Survey, originally developed by Madigosky et $a l^{12}$ for use in medical students. Previous studies among pharmacy students have focused on evaluating patient safety knowledge and practice beliefs using unvalidated survey tools, ${ }^{9} 10$ and attitudes to patient safety have been largely unstudied. Therefore, the aim of this study was to validate an adaptation of Madigosky et $a l \mathrm{~s}^{12}$ survey tool in order to evaluate patient safety attitudes and values of junior pharmacy students, and specifically understand the psychometric properties that underpin the survey.

\section{METHODS}

A cross-sectional survey was conducted among first $(n=281)$ and second $(n=269)$ year undergraduate pharmacy students enrolled in the 4-year Bachelor of Pharmacy programme at the University of Sydney. As both year groups would have completed an introductory pharmacy practice unit of study and introductory clinical placements (4 hours) at the time of survey completion, it was hypothesised that these two groups of students would have the most comparable clinical experience and be suitable participants in the validation of the survey instrument. Data were collected between 27 and 31 May 2013.

\section{Survey}

Survey modification

The survey tool was adapted from the Patient Safety/ Medical Fallibility Curriculum Survey developed by Madigosky et $a l^{12}$ Specifically, the original survey items that were included, suited first year Bachelor of Pharmacy students' level of knowledge and understanding of healthcare systems, which resulted in the exclusion of skill and knowledge-based items from the original survey. The survey consisted of two sections. The first section consisted of 23 attitudinal items, and included 17 of the original 18 attitudinal items and utilised the original five-point Likert-type scale to measure student attitudes, with possible responses ranging from strongly disagree to strongly agree. As the survey was being modified for pharmacy students, the use of the term 'physician' was changed to 'pharmacist' or 'medical practitioner' based on the item. Items that related to the reporting of errors were split into two items to evaluate whether students' responses would change due to the presence or absence of patient harm. In addition, two items to evaluate attitudes towards questioning more senior healthcare professionals, one item on patients' role in healthcare and one item on peer learning were added. The second section collected demographic details including gender, age, stage of education, prior healthcare experience and involvement with an incident that resulted in harm or potential harm as a result of receiving healthcare.

\section{Face validation}

The face validity of the survey instrument was assessed through focus groups among three populations: initially among five pharmacy academics, five practising pharmacists and seven pharmacy student representatives. Based on feedback from the three groups, one of the original questions relating to uncertainty in healthcare was considered ambiguous and was removed from the final survey tool. Pharmacy academics also perceived that due to junior pharmacy students' limited clinical experience, definitions of 'Patient Safety', 'Error' and 'Incident' should be included in the pretext to the survey. The student group were provided with terms defined by a range of healthcare organisations. As a result, the definitions used by the Australian Commission for Safety and Quality in Healthcare were selected due to both the perceived ease of understanding and perceived contextual relevance to junior pharmacy students. The final survey was approved by each group in a subsequent focus group.

\section{Analysis}

All data analyses were completed using IBM SPSS Statistics V.21 (SPSS Inc, Chicago, Illinois, USA) and AMOS V.21 (Amos Development Corporation, Crawfordville, Florida, USA). Surveys with missing data were excluded from the analysis. The survey response rate was calculated by dividing the total number of surveys completed by the number of students enrolled in each year group. Participant characteristics were compared across year groups using $\chi^{2}$ tests for categorical variables and Mann-Whitney and Kruskal-Wallis tests for continuous variables. In addition, the potential relationship between each of the participant demographic characteristics and their effects on survey responses were evaluated. A Bonferroni correction was applied to account for multiple comparisons, reducing the $\mathrm{p}$ value for significance to 0.002 .

An exploratory factor analysis (EFA) was performed on survey responses from the first year students to understand the latent structure underpinning student responses to the survey using maximum likelihood estimation and varimax rotation. As adequate sample sizes across both year groups were obtained, Kaisers criterion for factor retention was adopted with individual factors loading greater than 0.25 considered significant for retention. ${ }^{20}$ The factor structure was assessed for a theoretical basis, with an examination of the Scree plot used to verify the number of factors retained. 
The construct validity of the survey was evaluated using a confirmatory factor analysis (CFA) on the survey responses from the second year students. Each item was considered to have a latent construct and a measurement error, with both causal effects depicted by unidirectional arrows. Correlations between variables within the model were depicted using bidirectional arrows. ${ }^{21}$ Maximum likelihood estimation was performed to calculate item loading. Items were removed from the model where there were: poor factor loading scores (being less than 0.25), insufficient number of items loading on the construct, or an insufficient theoretical basis to the construct after item removal. ${ }^{20}$

Boomsma's method of estimating a minimum sample size to conduct a CFA was performed based on the number of items to number of factors ratio of the model; it was estimated that 200 student responses would be adequate. ${ }^{22}$ To evaluate the goodness of fit of the model, a number of fit statistics were examined. First, the $\chi^{2}$ statistic was used to evaluate model parsimony (ie, that the model accomplishes a desired level of explanation with as few variables and relationships between variables as possible). In addition, root meansquare error of approximation (RMSEA) was used to evaluate absolute fit (a measure of how well the data fits the proposed model) and the Comparative Fit Index (CFI) was used to evaluate the comparative fit (a measure of how well the data fits a model where relationships exist between the survey items compared to a model where no relationships exist). ${ }^{23} 24$

\section{RESULTS}

\section{Participant characteristics}

A total of 245 first-year and 201 second-year pharmacy students completed the survey, resulting in survey response rates of $87.5 \%$ and $74.7 \%$, respectively. The characteristics of the first and second year students are compared in table 1 . There were very few differences in the characteristics between the two groups of students, with the only significant difference being the number of students engaged in current employment in a pharmacy $(15.6 \%$ vs $44.4 \%, \mathrm{p}<0.001)$ and mean months worked
(2.4 vs $6.9, \mathrm{p}<0.001$ ). However, as most students that are engaged in employment in pharmacy are undertaking non-clinical roles $(19.7 \%$ vs $8.6 \%)$, it is unlikely that current employment will influence junior students' responses to the survey questions.

Comparisons of year group and other demographic characteristics with each of the survey items showed that demographic characteristics did not influence student responses after accounting for multiple comparisons with the Bonferroni correction (see online supplementary appendix 1). However, 2 of the 23 attitudinal items which related to the inevitability of errors in healthcare and involving the patient in healthcare, showed statistical significance between year groups $(p=0.001)$. Prior to the EFA, these items were removed as their exclusion was deemed not to have a significant impact on the model due to the inclusion of other survey items which measured similar concepts.

\section{Exploratory factor analysis}

Following the removal of seven items, either due to low communalities (less than 0.2) or low factor loadings (less than 0.25) and examination of the Scree plot, a five-factor solution was determined (table 2). This solution explained $55.71 \%$ of the variance. Only one item cross-loaded and was assigned to a single factor based on theoretical reasoning. The five factors were labelled as (1) being quality improvement focused; (2) value of contextual learning; (3) internalising errors regardless of harm; (4) acceptability of questioning more senior healthcare professionals' behaviour and (5) attitude towards open disclosure of errors.

\section{Confirmatory factor analysis}

In the second phase of the analysis, the construct validity of the instrument was established using CFA. After mapping the responses from the second year students to the suggested model determined by the EFA of first year students' responses, two items (Q5 and Q18) were removed due to low factor loading (less than 0.25), resulting in the final factor structure (table 3). The $\chi^{2}$ values for overall model fit was significant, $\chi^{2}$ (69)

\section{Table 1 Participant characteristics}

\begin{tabular}{|c|c|c|c|}
\hline Characteristic & $\begin{array}{l}\text { First year } \\
\text { students } \\
(n=245)\end{array}$ & $\begin{array}{l}\text { Second year } \\
\text { students } \\
(n=201)\end{array}$ & p Value \\
\hline \multicolumn{4}{|l|}{ Gender } \\
\hline Males, $\mathrm{n}(\%)^{*}$ & $90(36.9)$ & $65(32.8)$ & \\
\hline Females, $\mathrm{n}(\%)^{*}$ & $154(63.1)$ & $132(66.7)$ & 0.37 \\
\hline Age, in years, mean (SD) & $19.4(3.1)$ & $20.0(2.0)$ & $<0.001$ \\
\hline Students currently working in a pharmacy, $\mathrm{n}(\%)^{*}$ & $38(15.6)$ & $88(44.4)$ & $<0.001$ \\
\hline Months worked in pharmacy (mean, SD) & $2.4(9.5)$ & 6.7 (11.9) & $<0.001$ \\
\hline Students who have been involved in or witnessed harm while working, $\mathrm{n}(\%)^{*}$ & $21(9.7)$ & 29 (11.9) & 0.06 \\
\hline Students who have witnessed harm to a loved one, $\mathrm{n}(\%)^{*}$ & $35(15.9)$ & $35(19.1)$ & 0.14 \\
\hline
\end{tabular}




\begin{tabular}{|c|c|c|c|c|c|c|c|}
\hline \multirow[b]{2}{*}{$\begin{array}{l}\text { Question } \\
\text { number }\end{array}$} & \multirow[b]{2}{*}{ Item } & \multicolumn{5}{|c|}{ EFA constructs } & \multirow[b]{2}{*}{$\begin{array}{l}\text { Cronbachs } \alpha \\
\text { if item deleted }\end{array}$} \\
\hline & & $\begin{array}{l}\alpha=0.422 \\
\alpha\end{array}$ & $\begin{array}{l}2 \\
\alpha=0.673\end{array}$ & $\begin{array}{l}3 \\
\alpha=0.591\end{array}$ & $\begin{array}{l}4 \\
\alpha=0.533\end{array}$ & $\begin{array}{l}5 \\
\alpha=598\end{array}$ & \\
\hline Q7 & $\begin{array}{l}\text { Learning how to improve patient safety is an appropriate use of time in pharmacy } \\
\text { programmes at university }\end{array}$ & 0.62 & & & & & 0.22 \\
\hline Q3 & $\begin{array}{l}\text { Pharmacists should routinely spend part of their professional time working to } \\
\text { improve patient care }\end{array}$ & 0.48 & & & & & 0.32 \\
\hline Q23 & $\begin{array}{l}\text { Peer-led education, such as from pharmacist colleagues or fellow students can help } \\
\text { my understanding of patient safety concepts }\end{array}$ & 0.47 & & & & & 0.28 \\
\hline Q19 & The care that we provide on a day-to-day basis could be improved & 0.47 & & & & & 0.37 \\
\hline Q5 & Patients have a role to play in their own safety & 0.38 & & & & & 0.34 \\
\hline Q18 & After an error occurs, an effective strategy is to work hard to be more careful & -0.26 & & & & & 0.63 \\
\hline Q22 & Patient safety education requires university lecturers to teach patient safety concepts & & -0.78 & & & & 0.40 \\
\hline Q8 & $\begin{array}{l}\text { Healthcare professionals, including pharmacy staff, routinely share information about } \\
\text { errors and what caused them }\end{array}$ & & 0.76 & & & & 0.54 \\
\hline Q6 & $\begin{array}{l}\text { The culture of the pharmacy workplace makes it easy for pharmacy staff to deal } \\
\text { constructively with errors }\end{array}$ & & 0.40 & & & & 0.74 \\
\hline Q16 & If I saw an error that DID NOT cause harm, I would keep it to myself & & & 0.86 & & & 0.37 \\
\hline Q15 & If I saw an error that DID cause harm, I would keep it to myself & & & 0.48 & & & 0.49 \\
\hline Q14 & If there is no harm to a patient, there is no need to address an error & & & 0.42 & & & 0.58 \\
\hline Q10 & $\begin{array}{l}\text { Pharmacists should report errors to an affected patient and their family if harm to the } \\
\text { patient has occurred }\end{array}$ & & & & 0.97 & & - \\
\hline Q11 & $\begin{array}{l}\text { Pharmacists should discuss and report errors to an affected patient and their family } \\
\text { even if the patient is NOT harmed }\end{array}$ & & & & 0.38 & & - \\
\hline Q21 & $\begin{array}{l}\text { It is acceptable for a registered pharmacist to question the decisions of a prescriber } \\
\text { (such as a doctor or nurse practitioner) }\end{array}$ & & & & & 0.97 & - \\
\hline Q20 & $\begin{array}{l}\text { It is acceptable for an intern pharmacist to question the actions of a registered } \\
\text { pharmacist }\end{array}$ & 0.34 & & & & 0.36 & - \\
\hline
\end{tabular}

EFA, exploratory factor analysis. 
Table 3 Final CFA factor structure

\begin{tabular}{|c|c|c|c|c|c|}
\hline \multicolumn{2}{|c|}{ Explanation of factor structure } & $\begin{array}{l}\text { Standardised } \\
\text { regression weights }\end{array}$ & $\begin{array}{l}\text { Unstandardised } \\
\text { regression weights (URW) }\end{array}$ & $\begin{array}{l}\text { Standard error } \\
\text { of URW }\end{array}$ & $\begin{array}{l}\text { Squared multiple } \\
\text { correlations }\end{array}$ \\
\hline \multicolumn{6}{|c|}{ Factor 1: Being quality improvement focused $(\alpha=0.654)$} \\
\hline Q19 & $\begin{array}{l}\text { The care that we provide on a day-to-day basis could be } \\
\text { improved }\end{array}$ & 0.40 & 1.00 & 0.39 & 0.16 \\
\hline Q3 & $\begin{array}{l}\text { Pharmacists should routinely spend part of their professional } \\
\text { time working to improve patient care }\end{array}$ & 0.60 & 1.49 & 0.28 & 0.36 \\
\hline Q7 & $\begin{array}{l}\text { Learning how to improve patient safety is an appropriate use } \\
\text { of time in pharmacy programmes at university }\end{array}$ & 0.60 & 1.53 & 0.30 & 0.36 \\
\hline \multicolumn{6}{|c|}{ Factor 2: Internalising errors regardless of harm $(\alpha=0.705)$} \\
\hline Q16 & $\begin{array}{l}\text { If I saw an error that DID NOT cause harm, I would keep it to } \\
\text { myself }\end{array}$ & 0.72 & 1.00 & 0.45 & 0.52 \\
\hline Q15 & $\begin{array}{l}\text { If I saw an error that DID cause harm, I would keep it to } \\
\text { myself }\end{array}$ & 0.65 & 0.63 & 0.27 & 0.42 \\
\hline Q14 & $\begin{array}{l}\text { If there is no harm to a patient, there is no need to address } \\
\text { an error }\end{array}$ & 0.53 & 0.63 & 0.49 & 0.28 \\
\hline Q6 & $\begin{array}{l}\text { The culture of the pharmacy workplace makes it easy for } \\
\text { pharmacy staff to deal constructively with errors }\end{array}$ & -0.34 & -0.35 & 0.51 & 0.12 \\
\hline \multicolumn{6}{|c|}{ Factor 4: Acceptability of questioning more senior healthcare professionals' behaviour $(\alpha=0.718)$} \\
\hline Q20 & $\begin{array}{l}\text { It is acceptable for an intern pharmacist to question the } \\
\text { actions of a registered pharmacist }\end{array}$ & 0.64 & 1.00 & 0.31 & 0.40 \\
\hline Q21 & $\begin{array}{l}\text { It is acceptable for a registered pharmacist to question the } \\
\text { decisions of a prescriber (such as a doctor or nurse } \\
\text { practitioner) }\end{array}$ & 0.77 & 1.00 & 0.14 & 0.60 \\
\hline \multicolumn{6}{|c|}{ Factor 5: Attitude towards open disclosure of errors $(\alpha=0.534)$} \\
\hline Q10 & $\begin{array}{l}\text { Pharmacists should report errors to an affected patient and } \\
\text { their family if harm to the patient has occurred }\end{array}$ & 0.74 & 1.00 & 0.22 & 0.55 \\
\hline Q11 & $\begin{array}{l}\text { Pharmacists should discuss and report errors to an affected } \\
\text { patient and their family even if the patient is NOT harmed }\end{array}$ & 0.53 & 1.00 & 0.71 & 0.28 \\
\hline
\end{tabular}

CFA, confirmatory factor analysis. 
Figure 1 Final confirmatory factor analysis (CFA) model with factor loading calculated on combined first and second year data.

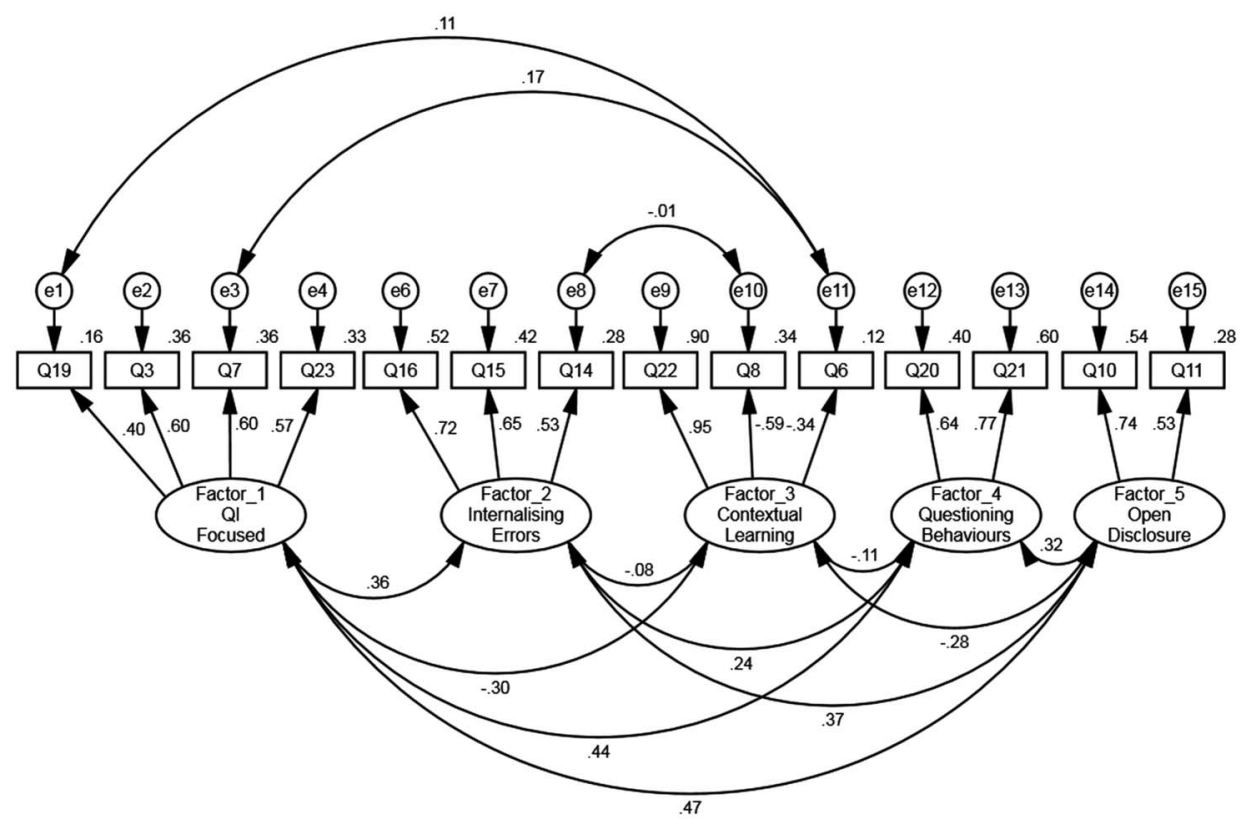

$=134.23, \mathrm{p}<0.001$, which suggested a significant misfit between the data and the model. However, it is known that in larger samples, the $\chi^{2}$ value can be over-sensitive and other fit indices were assessed (RMSEA $=0.07$ $\mathrm{CFI}=0.88$ ), which suggested potential fit. ${ }^{25}$ Modification indices suggested that freeing the covariance between two error terms in factor 1 , and one error term in factor 3 , as well as between one error term in factor 2 and one error term in factor 3, would improve model fit. A model including these specified correlations resulted in a subsequent model having better fit to the constrained model, $\chi^{2}(66)=112.83, p<0.001$, RMSEA $=0.06$, $\mathrm{CFI}=0.91$. Utilising data from both first year students and second year students as part of a multigroup analysis, unconstrained nested model comparisons showed no significant difference in the unconstrained model between year groups $\left(\Delta \chi^{2}(7)=3.079, \mathrm{p}=0.878\right)$. This indicates that both year groups satisfactorily fit the model. The combined data set of first and second year student responses $(\mathrm{N}=446)$ was used to calculate the final factor loadings as seen in figure 1 .

\section{DISCUSSION}

This study has validated a modified version of an existing patient safety attitudinal survey tool, the Patient Safety/ Medical Fallibility Curriculum survey, ${ }^{12}$ in pharmacy students. A robust two-staged analytical method, involving EFA followed by CFA, was used to assess the reliability and validity of the survey tool. The results of these analyses demonstrated that the attitudes which underpin students' responses could be explained by five underlying dimensions: (1) being quality improvement focused, (2) internalising errors regardless of harm, (3) value of contextual learning, (4) acceptability of questioning more senior healthcare professionals' behaviour and (5) attitude towards open disclosure of errors. Four of these dimensions related to patient safety attitudes (factors 1,2 , 4 and 5) and one pertained to the delivery of patient safety interventions (factor 3). This survey tool can therefore be used to help assess the educational needs of students and evaluate patient safety educational interventions. ${ }^{26}$

The first factor pertained to willingness to undertake quality improvement activities. The EFA on first year students' responses revealed a relatively low internal consistency reliability for this factor (Cronbach $\alpha=0.422$ ). Two items (Q5-Patients have a role to play in their own safety and Q18-After an error occurs, an effective strategy is to work hard to be more careful) had a relatively low loading on the factor and made little contribution to the meaning of the factor. After the removal of these items during the CFA process, there was a significant improvement in the Cronbach $\alpha$ in second year responses (0.654), thereby demonstrating improved internal consistency. This factor examined a positive attitude towards patient safety. Specifically this factor, focused on quality improvement as an indicator of positive safety culture, with higher scores indicating a greater emphasis towards taking a systems approach to dealing with errors, a desired outcome of many patient safety programmes. ${ }^{27}$ The second factor, however, measured a negative attitude toward patient safety. This factor related to managing and reporting risk, whereby students internalise the error rather than take action, regardless of whether the patient suffered harm. Thus higher scores indicate that students may be less likely to appropriately manage an error. Scores on these factors are important given that there is a push towards teaching incident reporting from junior years to foster good behaviours and to develop a culture of understanding and preventing errors. ${ }^{28}$ Consequently, as students become more quality improvement focused (as measured by factor 1 ), it would be expected that they would 
be more likely to appropriately manage an error rather than internalising the issue (resulting in a corresponding decrease in scores on factor 2). ${ }^{29}$

The fourth factor measured how acceptable it is to students to question the decisions of more senior healthcare professionals, an important part of managing risk in healthcare. While the two items in this scale are clearly related, these two items do differ significantly. The first item in the factor relates to questioning the decision of a prescriber, while the second item relates to the questioning of an action of a more senior pharmacist. Previous studies have identified that a major obstacle to good patient safety practices among students is the hierarchical structure of healthcare organisations, including community pharmacies where most pharmacy students obtain their first clinical experience. ${ }^{30} 31$ Being able to work well within teams has been associated with reduced medical errors and improved outcomes in primary healthcare. ${ }^{32-34}$ In addition to effective communication, being able to deal with conflict, particularly with more senior healthcare practitioners, is also considered an important skill. ${ }^{35}$ Many patient safety education programmes now include training in managing situations resulting in conflict, and while this factor may not be able to directly examine this skill, by measuring students' attitudes, it indirectly evaluates whether there is a need for further training in this area.

A core element of all patient safety programmes is the concept of patient-centred care, which includes involving the patient in decisions about their own care and openly disclosing incidents when they occur. Factor five related to open disclosure of errors and hence may be used as a measure of students' willingness to openly disclose errors to patients, regardless of whether or not harm occurs. Despite being uncommon in practice, open disclosure of errors by healthcare practitioners is desired by patients and required by healthcare authorities. ${ }^{36}$ Furthermore, it has been shown that it is important for educators to start open disclosure training as early as possible in order to have the greatest impact on changing this behaviour. ${ }^{37}$

The final factor (factor 3) related to the educational delivery of patient safety interventions. It focused on the pedagogical method that would be most effective in delivering patient safety education to junior pharmacy students $^{26}$ with items relating to the didactic method of teaching patient safety through university lectures, and learning from experience in the workplace. It is known that the learning preferences of students change throughout their degree, with more meaning-directed approaches preferred as they progress through their degree. ${ }^{38}$ This factor may therefore be useful to guide the development of teaching materials, tailored to better suit students' learning style preferences.

Despite the survey being used previously in evaluating patient safety attitudes of both medical and nursing students, only one study has investigated the psychometric properties of the original survey. ${ }^{15}$ Schnall $e t a l^{15}$ utilised
17 of the skill and attitudinal items from the original survey to identify a nine-item, three-factor solution: 'Error detection, time investment and creating a culture of safety'. Five of the nine items included in Schnall's factor analysis were also included in our final CFA model, however, were placed under different factors in our analysis. Like Schnall et al, the present study observed low reliability scores in our factors during the EFA with first year students. However, when applying the EFA factor structure to our second year students, reliability scores increased, which indicates that students may understand and relate to survey items better the further they have progressed in their degrees as a result of receiving more practice-specific education.

\section{Implications for educators}

The use of this survey tool provides a number of benefits for educators. Given that the literature identifies a significant need to provide more training to pharmacy and other healthcare students on all aspects of patient safety, it is crucial that pharmacy schools have a mechanism for evaluating the impact of these programmes. ${ }^{26}{ }^{39-41}$ It is noteworthy that current patient safety programmes for pharmacy students often include elements of identifying, understanding, reporting, managing and communicating risk. The underlying attitudes leading to the practice of these positive safety behaviours can all be evaluated using the survey tool. In addition, there are a number of potential benefits which may arise through the repeated use of this tool throughout a student's degree programme. First, it will provide a means to evaluate the longitudinal effect of patient safety education interventions and changes in students' attitudes. It can also be used to measure the effect of the informal and hidden curricula on students' patient safety attitudes, which is particularly important as students start experiential learning placements and as more students engage in casual employment in assistance roles. Thus the evaluation of these changes can provide useful information about the educational needs of students through their degrees and when additional and more targeted interventions will need to be provided.

\section{Strengths and limitations of this study}

This study has a number of strengths. First, in the absence of a published survey tool to evaluate the patient safety attitudes of pharmacy students, this study modified one of the most highly utilised survey tools to measure the patient safety attitudes of healthcare students ${ }^{12} 1315$ in order to suit the requirements of junior pharmacy students. Furthermore, the relatively large sample size obtained ( $\mathrm{N}=446)$ allowed for a rigorous analytical approach to be undertaken, enabling both exploratory factor analysis and confirmatory factor analysis (CFA) to be performed with sufficient sample sizes for validation of the survey tool. In addition, the high response rates of students completing the survey $(87.5 \%$ of first year students and $74.7 \%$ of second year students) means that the 
findings are likely to be representative of the attitudes of junior pharmacy students undertaking the Bachelor of Pharmacy programme at the University of Sydney. However, as the sample was drawn exclusively from a single institution, the findings may not be representative of students enrolled in other pharmacy programmes. In addition, despite test-retest reliability not being performed, conducting a CFA on data collected at the same time ensured a form of reliability in the study. Finally, two of the factors (factor 4-questioning behaviours and factor 5-open disclosure) consisted of only two items. While this is considered acceptable, ${ }^{42}$ it is also a potential limitation that is likely a consequence of the relatively short survey tool utilised. However, the two items that loaded on these two factors adequately described the latent concepts being measured, and are appropriate to the level of understanding and knowledge that junior pharmacy students have of the healthcare system.

\section{CONCLUSION}

This study has demonstrated the validity of a tool to evaluate the attitudes of pharmacy students across a number of patient safety areas. Given that there is growing recognition of the need to educate pharmacy students in patient safety concepts, this survey can be used by pharmacy schools to evaluate the underlying dimensions of students' patient safety attitudes, which have direct effects on the manner in which students practice. Through the use of this tool, pharmacy schools will be able to further develop and tailor their patient safety training to better suit students' educational needs.

Acknowledgements The authors would like to thank the Faculty of Pharmacy for supporting this project and the undergraduate students who participated in this study.

Contributors RLW conceived and designed the study, collected and analysed the data and drafted the manuscript. RAF assisted in the design of the study, analysis of the results and revised the manuscript. SRC assisted in the analysis of the results and revised the manuscript. AJM and TFC assisted in the design of the study and revised the manuscript.

Funding This work was supported by the International Pharmaceutical Federation's (FIP) Young Pharmacist/Pharmaceutical Scientist Grant for Professional Innovation 2012. FIP had no involvement in the development, execution or evaluation of this study.

Competing interests None declared.

Ethics approval Human Research Ethics Committee, The University of Sydney (project number 2013/219).

Provenance and peer review Not commissioned; externally peer reviewed.

Data sharing statement No additional data are available.

Open Access This is an Open Access article distributed in accordance with the Creative Commons Attribution Non Commercial (CC BY-NC 4.0) license, which permits others to distribute, remix, adapt, build upon this work noncommercially, and license their derivative works on different terms, provided the original work is properly cited and the use is non-commercial. See: http:// creativecommons.org/licenses/by-nc/4.0/

\section{REFERENCES}

1. Kohn LT, Corrigan J, Donaldson MS. To err is human: building a safer health system. Washington, DC: Institute of Medicine, 2000.
2. Department of Health. An organisation with a memory. London, UK: Department of Health, 2000.

3. Teigland CL, Blasiak RC, Wilson LA, et al. Patient safety and quality improvement education: a cross-sectional study of medical students' preferences and attitudes. BMC Med Educ 2013;13:16.

4. Nie Y, Li L, Duan Y, et al. Patient safety education for undergraduate medical students: a systematic review. BMC Med Educ 2011;11:33.

5. Sandars J, Bax N, Mayer D, et al. Educating undergraduate medical students about patient safety: priority areas for curriculum development. Med Teach 2007;29:60-1.

6. Marriott JL, Nation RL, Roller L, et al. Pharmacy education in the context of Australian practice. Am J Pharm Educ 2008;72:126.

7. Henderson D, Carson-Stevens A, Bohnen J, et al. Check a box. Save a life: how student leadership is shaking up health care and driving a revolution in patient safety. J Patient Saf 2010;6:43-7.

8. Kebede $S$, Pronovost $\mathrm{P}$. It is time to reinvent the wheels of medical training. Acad Med 2015;90:126.

9. Kiersma ME, Darbishire PL, Plake KS, et al. Laboratory session to improve first-year pharmacy students' knowledge and confidence concerning the prevention of medication errors. Am J Pharm Educ 2009;73:99.

10. Sukkari SR, Sasich LD, Tuttle DA, et al. Development and evaluation of a required patient safety course. Am J Pharm Educ 2008;72:65

11. Bentler PM, Speckart G. Attitudes "cause" behaviors: a structural equation analysis. J Pers Soc Psychol 1981;40:226-38.

12. Madigosky WS, Headrick LA, Nelson K, et al. Changing and sustaining medical students' knowledge, skills, and attitudes about patient safety and medical fallibility. Acad Med 2006;81:94.

13. Leung GK, Patil NG. Patient safety in the undergraduate curriculum: medical students' perception. Hong Kong Med J 2010;16:101-5

14. Halbach JL, Sullivan LL. Teaching medical students about medical errors and patient safety: evaluation of a required curriculum. Acad Med 2005;80:600-6.

15. Schnall R, Stone P, Currie L, et al. Development of a self-report instrument to measure patient safety attitudes, skills, and knowledge. J Nurs Scholars 2008;40:391-4.

16. Flin R, Patey R, Jackson J, et al. Year 1 medical undergraduates' knowledge of and attitudes to medical error. Med Educ 2009;43:1147-55

17. Dudas RA, Bundy DG, Miller MR, et al. Can teaching medical students to investigate medication errors change their attitudes towards patient safety? BMJ Qual Saf 2011;20:319-25.

18. Moskowitz E, Veloski JJ, Fields SK, et al. Development and evaluation of a 1-day interclerkship program for medical students on medical errors and patient safety. Am J Med Qual 2007:22:13-17.

19. Kiersma ME, Plake KS, Darbishire PL. Patient safety instruction in US health professions education. Am J Pharm Educ 2011;75:162.

20. Tabachnick BG, Fidell LS. Using multivariate statistics. 6th edn. New Jersey, NJ: Pearson, 2013.

21. Schreiber JB. Core reporting practices in structural equation modeling. Res Social Adm Pharm 2008;4:83-97.

22. MacCallum RC, Widaman KF, Zhang S, et al. Sample size in factor analysis. Psychol Methods 1999;4:84.

23. Fan X, Thompson B, Wang L. Effects of sample size, estimation methods, and model specification on structural equation modeling fit indexes. Struct Equ Modeling 1999;6:56-83.

24. Bentler PM. Comparative fit indexes in structural models. Psychol Bull 1990;107:238-46.

25. Kline RB. Principles and practice of structural equation modeling New York, NY: Guilford Publications, 1998.

26. Holdford DA, Warholak TL, West-Strum D, et al. Teaching the science of safety in US colleges and schools of pharmacy. Am J Pharm Educ 2011;75:77.

27. Thompson DA, Cowan J, Holzmueller C, et al. Planning and implementing a systems-based patient safety curriculum in medical education. Am J Med Qual 2008;23:271-8.

28. Seiden SC, Galvan C, Lamm R. Role of medical students in preventing patient harm and enhancing patient safety. Qual Saf Health Care 2006;15:272-6.

29. Ullström S, Sachs MA, Hansson J, et al. Suffering in silence: a qualitative study of second victims of adverse events. BMJ Qual Saf 2014:23:325-31.

30. Phipps DL, Noyce PR, Parker D, et al. Medication safety in community pharmacy: a qualitative study of the sociotechnical context. BMC Health Serv Res 2009;9:158.

31. Lalor DJ, Chen TF, Walpola R, et al. An exploration of Australian hospital pharmacists' attitudes to patient safety. Int J Pharm Pract 2015;23:67-76. 
32. Stevenson $\mathrm{K}$, Baker R, Farooqi A, et al. Features of primary health care teams associated with successful quality improvement of diabetes care: a qualitative study. Fam Pract 2001;18: 21-6.

33. Morey JC, Simon R, Jay GD, et al. Error reduction and performance improvement in the emergency department through formal teamwork training: evaluation results of the MedTeams project. Health Serv Res 2002;37:1553-81.

34. Risser DT, Rice MM, Salisbury ML, et al. The potential for improved teamwork to reduce medical errors in the emergency department. Ann Emerg Med 1999;34:373-83.

35. Robertson B, Kaplan B, Atallah $\mathrm{H}$, et al. The use of simulation and a modified TeamSTEPPS curriculum for medical and nursing student team training. Simul Healthc 2010;5:332-7.

36. Finlay A, Stewart CL, Parker M. Open disclosure: ethical, professional and legal obligations, and the way forward for regulation. Med J Aust 2012;198:445-8.
37. White AA, Gallagher TH, Krauss MJ, et al. The attitudes and experiences of trainees regarding disclosing medical errors to patients. Acad Med 2008;83:250-6.

38. Smith L, Krass I, Sainsbury E, et al. Pharmacy students' approaches to learning in undergraduate and graduate entry programs. $A m \mathrm{~J}$ Pharm Educ 2010;74:106.

39. Wetzel AP, Dow AW, Mazmanian PE. Patient safety attitudes and behaviors of graduating medical students. Eval Health Prof 2011;35:221-38.

40. Waterson P, Griffiths P, Stride C, et al. Psychometric properties of the hospital survey on patient safety culture: findings from the UK. Qual Saf Health Care 2010;19:e2.

41. Bradley F, Steven A, Ashcroft DM. The role of hidden curriculum in teaching pharmacy students about patient safety. Am J Pharm Educ 2011;75:143.

42. Kenny DA, Kashy DA, Bolger N. The handbook of social psychology. 4th edn. New York, NY: McGraw-Hill, 1998. 